\title{
OS TENIWOHA NOS PRIMEIROS TRATADOS DOS POEMAS RENGA DA ERA MEDIEVAL JAPONESA
}

\section{Eliza Atsuko Tashiro-Perez}

\begin{abstract}
Resumo: Dando continuidade ao estudo sobre os morfemas gramaticais chamados teni(wo)ha nos tratados poéticos, neste artigo apresentamos os documentos da poesia renga. Sobre os da poética do waka foram apresentados em Tashiro-Perez 2009. Neste artigo tentamos interpretar alguns comentários dos autores acerca da importância dos teni(wo)ha nos poemas renga. E também quadros-resumo dos tipos de teni(wo)ha explicados em cada obra, estabelecendo paralelo com a classe dos morfemas joshi, de Yoshio Yamada (1873-1958). E, na parte final deste texto, introduzimos alguns estudos dos períodos Meiji, Taisho e início de Showa sobre os morfemas teni(wo)ha, os quais passam a receber nova denominação e definição gramatical mais precisa por meio de tentativas de buscar especificidades da língua japonesa.

Palavras-chave: japonês medieval; teni(wo)ha; morfemas gramaticais; poemas renga
\end{abstract}

\begin{abstract}
Continuing the studies on grammatical morphemes named teni(wo)ha this article presents the treaties on renga poetics. In Tashiro-Perez 2010, I have presented early treaties on waka poetics. In this article we try to interpret some comments about the importance of teni(wo)ha in renga poe$\mathrm{ms}$. And also frames-summary of types of teni(wo)ha explained in each work, establishing parallel with the class of joshi, defined by Yoshio Yamada (1873-1958). And, at the end of this text, we have introduced some studies of Meiji, Taisho and early Showa periods about morphemes teni(wo)ha, which shall receive new names and grammatical and more precise definition through attempts to seek specifics of the Japanese language.
\end{abstract}

Keywords: medieval Japanese; teni(wo)ha; grammatical morphemes; renga poetry

\section{Introdução}

Renga pode ser traduzida como poesia em cadeia e é a denominação geral usada para o tan renga (poesia curta em cadeia) que se fazia no Período Heian e para o chô renga (poesia longa em cadeia) produzido entre o Período Kamakura e o Edo. 
O tan renga mais antigo está registrado no volume oito da coletânea Man'yôshû (Compilação de Dez Mil Folhas, c. 759). Trata-se do poema de número 1.635 , o qual foi composto por Yakamochi Ôtomo (715-785), um dos compiladores da coletânea, conjuntamente com uma monja. O tan renga era composto da seguinte forma: um dos poetas elaborava uma das estrofes (de 5, 7 e 5 sílabas ou de 7 e 7 sílabas) e outro poeta fazia a outra estrofe para completar e formar um único poema.

No fim do Período Heian, surgiu o chô renga, chamado na época kusari renga (poesia encadeada, em corrente). Era um poema longo formado por estrofes alternadas de 5,7 e 5 sílabas ou 7 e 7 sílabas, na maioria das vezes feito por vários autores. Como foi muito apreciado pelo imperador Gotoba (1180-1239) e por poetas da nobreza como Teika Fujiwara (1162-1241) e Ietaka Fujiwara (11581237), tornou-se uma literatura da corte imperial e tomou formato próprio. Isso levou a que fossem produzidas tábuas de códigos para sua composição chamadas shikimoku. Hoje, quando se fala em renga, ele se refere, justamente, a esse kusari renga.

Paralelamente à conquista do prestígio na aristocriacia, em meados do século XIII, o kusari renga passou a ser praticado pela população em geral, fora do círculo da corte imperial e da nobreza, sob a orientação de mestres do renga, chamados jige ${ }^{1}$ rengashi ou mestres populares do renga. Esses mestres reuniam a população sob as cerejeiras de templos budistas para encontros poéticos, que foram responsáveis pela difusão do renga num espaço territorial amplo e proporcionaram o surgimento de notáveis poetas, dentre eles Gusai (c.1283-c.1376). Na segunda metade do século XIV, o renga transformou-se na poesia por excelência da época, suplantando o waka. O kampaku da corte imperial do Norte, Yoshimoto Nijô (1320-1388), discípulo de Gusai, foi o protagonista desse florescimento do renga. No fim desse século, outro discípulo de Gusai, Shû'a (n.d.-c.1377) se notabilizou como poeta de renga e desenvolveu estilo considerado de primor formal.

Por essa época, a população passou a compor para concorrer em competições de renga, o que, na opinião dos atuais críticos literários, diminuiu a qualidade dos poemas devido à excessiva preocupação com a forma. A recuperação do classicismo e o refinamento contido na ideia do ushin renga viriam com os poetas Sôzei (n.d.-1455) e Chi'un (n.d.-1448), seguidos por Shinkei (1406-1475), Senjun (14111476), No'a (n.d.), entre outros. Herdeiro do estilo de Sôzei, Shinkei e Senjun, o monge Sôgi (1421-1502) veio a se tornar o grande mestre do renga, aglutinando as tendências anteriores a ele em Chikurinshô (Notas num Bosque de Bambus, 1476) e Shinsen Tsukubashû (Nova Coletânea de Poemas de Tsukuba, 1495) e escrevendo tratados como Azuma Mondô (Diálogos em Azuma, c.1467), Oi-

1. Refere-se a pessoas que não tinham trânsito na corte imperial e nos palácios da aristocracia. 
-no Susami (Diversões na Velhice, 1495). Com seus discípulos, compôs Minase Sangin Hyakuin (Cem Poemas Compostos por Três Poetas em Minase, 1488).

Já no Período Azuchi Momoyama (c.1568-c.1598), o poeta representativo da época foi Joha (1525-1602), que foi mestre de muitos senhores feudais, entre os quais Hideyoshi Toyotomi (1537-1595). Em meados do século XVI, o renga conheceu a sua decadência e foi substituído pelo haikai. O renga era uma literatura da aristocracia, intimamente ligada à tradição do waka e prezava a elegância clássica. O haikai-no renga, do qual se autonomizou o haikai, é produto do Período Edo, época de ascensão dos comerciantes. Nesse panorama, a nova forma estética surgiu para representar a vitalidade e a diversidade de uma nova ordem social.

O poeta Makoto Ôka (1991: 131-135) lembrou o poder que esta forma antiga de poesia possuía para inspirar poesia e unir poetas. Na verdade, Ôka refere-se ao haikai que se originou do renga e foi cultuado no Período Edo e que ainda hoje se pratica, mas sem a preocupação com o fazer coletivo por parte dos compositores atuais, que se limitariam à composição individual. De qualquer maneira, Ôka sentiu, com base em uma experiência vivida, que essa tarefa coletiva colabora para criar um clima saudável de amizade entre os poetas que participam do 'jogo' Isso porque no renga e também no haikai-no renga, que se originou do primeiro, participavam vários poetas, num exercício em que cada um "iguala sua individualidade com a do outro poeta para obter o mais alto entendimento estético. Isto leva para a harmonia e equilíbrio inatingível por qualquer um individualmente". Na verdade, Ôka redescobriu na poesia clássica japonesa o processo pelo qual "o pensamento solitário de um poeta interage com o de outros num "banquete"" e apostou que tal procedimento "pode abrir novas possibilidades para a poesia contemporânea"

Criação essencialmente coletiva, o lugar para a reunião dos poetas, cujo número ideal parece ter sido 7 ou 8, revestia-se de importância no renga. $\mathrm{O}$ ambiente podia ser externo, sob cerejeiras, por exemplo, ou interno. $O$ espaço de reunião era, a um tempo, local de harmonização entre os poetas e, também de competição que gerava rivalidades. Por isso, tornaram-se necessários um organizador e um escrivão, o que fez surgir os rengashi ou mestres do renga.

A estrofe de entrada do renga, de 5, 7 e 5 sílabas, chama-se hokku. A estrofe seguinte, chamada $t$ sukeku, continha 7 e 7 sílabas; a terceira, denominada sanku, tinha 5, 7 e 7 sílabas novamente. Assim, os poetas, sucessivamente, iam alternando os formatos 5, 7 e 7, de um lado, e, de outro, de 7 e 7, até chegar na última estrófe, chamada ageku. As outras estrofes intermediárias são denominadas hiraku. Alguns poemas com número determinado de estrofes têm nomes especiais: há renga de 100 estrofes, chamada hyakuin; de 36, de nome kasen; de 44 estrofes, chamado yoyoshi; de 50, chamado gojuin; e de 10.000, chamado manku.

No processo de criação do renga, dois cuidados eram importantes: tsukeai $\mathrm{e}$ yukiyô. Os poetas, ao elaborarem a sua estrofe, atentando para a que foi elaborada antes, não deveriam se descuidar do clima ou da harmonia geral do poema como 
um todo. Essa observância da harmonia de conjunto recebe o nome de yukiyô e os cuidados realtivos a isso estavam contidos nos citados shikimoku ou códigos do renga. Cada estrofe acabava se tornando um pequeno poema, completo na semântica da poesia, diferente a completude sintática, e criava um pequeno mundo. Essa preocupação que o poeta necessitava ter em relação à estrofe anterior chamou-se tsukeai e provocou a produção de diversos tratados com regras para sua prática.

Os temas preferidos da criação do renga, antes de se transformar no haikai-no renga, foram os mesmos assuntos de estética da poesia waka: as estações do ano, o amor e miscelâneas que enfocavam viagens, reminiscências etc.. Quando o renga tomava a forma de um hyakuin (renga de 100 estrofes), vários temas podiam aparecer esparsos, mas com certo ordenamento.

\section{A Poesia Renga e os Tratados sobre os Teniwoha}

A seguir, descreveremos a caracterização geral dos tratados sobre o renga que trataram pioneiramente os morfemas teni( wo ha, expondo informações sobre a sua autoria, o tipo de documentação, assim como sobre as características de sua produção e recepção.

Renrihishô (Segredos da Composição do Renga)

Autor: Yoshimoto Nijô (1320-1388)

Título completo: o mesmo

Ano de elaboração: 1349

Língua descrita: língua japonesa clássica, da linguagem da poesia ou kago Língua de descrição: japonês medieval

Tipo de documentação: tratado para a criação do poema renga

O autor deste tratado, Yoshimoto Nijô, foi alto funcionário do governo e poeta de waka e renga. Pertencia à nobreza embora a aristocracia tivesse, em sua época, perdido o poder político. Mesmo assim, foi conselheiro de três xoguns. Cedo se iniciou na arte do renga e produziu diversos trabalhos relacionados à poesia: Tsukubashû (Antologia de Tsukuba, 1356-1357), uma grande coletânea de renga, e elaborou um código (ou shikimoku) sobre a composição do renga, o Renrishinshiki (Novo Segredo de Composição do Renga, 1372). Além disso, sua produção crítica incluiu, além do Renrihishô, Tsukuba Mondô (Diálogos de Tsukuba, 1357-1372) e Kyûshû Mondô (Diálogos de Kyûshû, 1376). Seus poemas estão compilados em Bunna Senku (Mil Poemas do Período Bunna, 1355) e em Ishiyama Hyakuin (Cem Poemas em Ishiyama, 1385). 
Renrihishô contém um prefácio do monge Gen e (n.d.-1350) e um posfácio escrito por outro poeta de renga, Gusai (c.1284-c.1378), seu mestre. Trata-se de um manual secreto sobre a composição do poema renga destinado aos iniciantes, que explica o modo de aprendizagem dessa arte e a postura espiritual dos seus praticantes. Trazia, nas últimas páginas, o 'código' vigente na época acerca da criação do renga.

O interesse pela explicação - não obstante a sua relativa superficialidade, possivelmente conseqüência da estrutura do manual pautada na tradição da transmissão dos ensinamentos de mestre para discípulo - dos teniwoha parece dever-se ao fato de, no poema renga, tais formas serem cruciais para a relação semântica entre as estrofes.

Esta documentação foi importante para as pesquisas sobre teniwoha por apresentar as seguintes características:

1) registrou a tipologização das 'palavras' em três tipos concebendo-os contrastivamente: entre teniwoha e mono-no na (nomes) e entre teniwoha $\mathrm{e}$ kotoba (outras palavras lexicais, subtraídos os mono-no na), que podemos esquematizar como abaixo:

\section{Quadro 1: tipologização das palavras segundo Renrihishô (Segredos da Composição do Renga):}

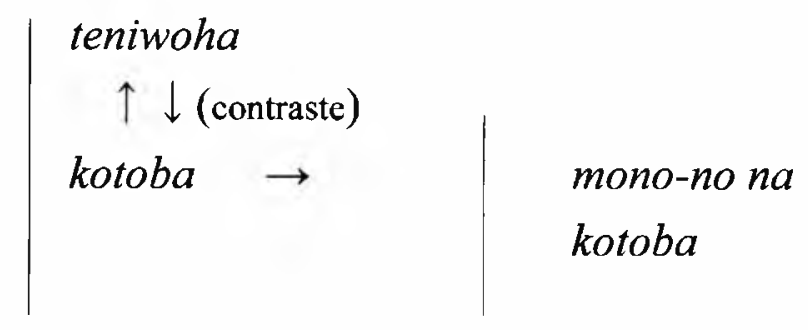

2) atestou o reconhecimento da importância dos teniwoha nos poemas renga

$\mathrm{O}$ parágrafo "Teniwoha-wa daji-no koto nari ( $\mathrm{O}$ teniwoha é uma coisa importante)" tem sido utilizado pelos lingüistas japoneses para comprovar a importância dada por Yoshimoto Nijô aos teniwoha. Nele, o poeta mencionou cinco letras - usa-se a palavra ji correspondiam aos teniwoha: no, te, temo, tomo e no, que deviam ser usados, ou não, em determinados versos do renga. 
3) apresentou visão precursora sobre os kireji (letra de corte) que, de um recurso estilístico, passou a denominar a letra, ou o teniwoha, que produzia o efeito do corte.

Yoshimoto citou, mas não explicou, as letras ou palavras seguintes como sendo kireji: kana, keri/kere, nashi, nare e ran.

Bajôshû (Escritos [Andando] a Cavalo)

Autor: provelmente Shinkei (1406-1475).

Ano de elaboração: caso se aceite a autoria de Shinkei, antes de 1475

Língua descrita: língua japonesa clássica, da linguagem da poesia (kago)

Língua de descrição: japonês medieval

Tipo de documentação: tratado de produção do poema renga

Shinkei foi poeta de waka e renga e monge budista. Aprendeu waka de Shôtetsu (1381-1459), da Escola de poetas Reizei. Não se conhece quando e como ele se iniciou no renga. Em 1463, Shinkei fez uma viagem de Quioto a região de Kii (hoje, província Wakayama) e durante o trajeto escreveu Sasamegoto (Sussurros, 1463). Três anos depois, reuniu seus poemas em uma antologia, o Shinkei Kushû (Seleções de Poemas de Shinkei, 1466). A partir de 1467 saiu em repetidas viagens fugindo dos distúrbios em Quioto ocasionados pela Rebelião de Ônin (1467-1477).

No tratado Bajôshû, o autor afirmou a existência, também na poética do renga, da preocupação com o teniwoha e indicou que o seu uso nos renga envolvia segredos de transmissão oral, de mestre para discípulo. Nota-se, nesse tratado, a ampliação do leque de palavras que na época o autor entendia como teniwoha, chegando a abarcar sob essa denominação também expressões e advérbios como ate.

Neste tratado, assim como acontecia com os tratados sobre waka, há referências sobre a regra do kakari musubi, brevemente explicado em Tashiro-Perez (2009).

Foi o primeiro tratado do renga no qual teve lugar o termo kireji (切字, letras de corte) dos quais o autor apontou a existência de 18 deles, embora não os tenha elencado no texto.

Hakuhatsushû (Escritos do [Homem] Grisalho)

Autor: Joha (1527-1602)

Ano de elaboração: desconhecido

Língua descrita: japonês clássico, da linguagem da poesia

Língua de descrição: japonês medieval

Tipo de documentação: tratado para a produção do poema renga 
Para justificar o estranho título dado ao tratado, Joha escreveu que, em sonho, ao declamar o hokku (a estrofe de entrada) "tsuki-ha kesa omi-no hana-ho katamisô", um idoso de cabelos completamente grisalhos chamou-lhe a atenção para a ausência de kireji (letra de corte). É o tratado que consolidou as regras de uso do kireji no renga e contém uma lista com 18 kireji.

\section{Sobre os Kireji}

Kireji significa letra ou sílaba de corte. Na poética do renga e do haikai, são expressões que finalizam a estrofe ou verso, tais como, kana, keri, ran, ya etc. Em certas estrofes, como a primeira e a terceira, supõe-se o emprego obrigatório de um deles.

Nagayama (1963), colocando em dúvida a afirmação do estudioso Yoshio Yamada (1873-1958) de que o primeiro tratado a abordar a teoria do kireji foi Renrihishô (1349), fez um recuo maior no tempo e defendeu que a idéia do kireji, embora sem essa designação, já aparecia em Toshiyori Zuinô (O Essencial da Poética de Shunrai, c.1115), de Toshiyori Minamoto (c.1055-c.1129), e em Fukurozôshi (Livro de Páginas Dobradas, c.1156), de Kiyosuke Fujiwara (11041177). Toshiyori declarou que cada estrofe de um renga (aqui, se referindo a tan renga [renga curto]), em especial a inicial, deveria conter a idéia completa do autor. E justificou que isso se fazia necessário para o desenvolvimento do processo de criação do renga, pois, do contrário, o autor seguinte teria que complementar a idéia incompleta da primeira estrofe. A teoria do kireji surgiu, portanto, como uma regra crucial para a própria elaboração do renga. Kiyosuke, em Fukurozôshi, expressou conselhos de igual teor e, para isso, usou o verbo iikiru, no qual aparece kiru, também um verbo, que daria origem a kireji (letra de corte). Iikiru passou a denominar a ação de elaborar uma estrofe, encerrando nesse limite, uma idéia poética completa. Nagayama destacou que, no ensinamento desses dois poetas, a idéia de kireji referia-se à completude de idéias que deveria ser alcançada.

Em Yakumomishô (O Tratado de Sua Majestade Yakumo, ano de elaboração desconhecido), do imperador Juntoku (1197-1242), a completude de idéias no hokku (estrofe de entrada) do renga mereceu atenção. Passaram a ser elaboradas regras de conteúdo lingüistico com explicitação de expressões que funcionariam ou não como marcas de completude do hokku. Esse interesse coincidiu com o prestígio que o chô renga (renga longo) conquistava no meio artístico aristocrático e na corte imperial. Já se elaboravam hyakuin, ou renga de 100 estrofes. Paralelamente ao aprimoramento poético e técnico por que passava a poesia renga, os seus tratados, de igual modo, foram tomando formas mais claras, contendo regras concretas de ensinamento. No caso da construção do renga de 100 estrofes, foi estabelecido o número máximo de estrofes sem iikiri; e instituiu-se que o hokku 
obrigatoriamente deveria apresentá-lo. O florescimento do chô renga (renga longo) aumentou a importância da estrofe de entrada para a sua composição. Como exemplo das regras a serem seguidas com vistas à completude dessa estrofe inicial, diz o Hekirenshô (Tratado sobre Renga de um Errante, 1345): no, ha(wa) e wo na posição final do hokku não é bom; no entanto o uso de kana, beshi ou de um mono-no na (nome) é bom.

Nessa época, ainda não aparecia o termo kireji. Pelas mãos de mestres do renga, o monge Gusai (c.1283-c.1376) e Yoshimoto Nijô (1320-1388), o renga alcança o status de manifestação literária da aristocracia e foi nos primeiros tratados de Yoshimoto que apareceu o termo kireji. Nagayama (1963) explica que, ainda assim, as formas gramaticais citadas e apresentadas por Yoshimoto não foram abordadas propriamente como kireji mas, sim, como palavras que eram de emprego obrigatório numa estrofe de entrada. Em outras palavras, o uso do kireji era explicado em função da forma do hokku, não se constituindo, portanto, uma teoria autônoma sobre o kireji. Além disso, os kireji incluíam expressões um pouco mais extensas, além dos morfemas gramaticais.

$\mathrm{O}$ apogeu da poética do renga aconteceu na época dos poetas-monges Sôzei (n.d.-1455), Shinkei (1406-1475), Senjun (1411-1476). Em Mitsudenshô (Tratados Secretos), de Sôzei, pela primeira vez o kireji passou a ser chamado kire teniha e, paralelamente, foi limitado aos morfemas teniwoha, eliminando-se outras expressões. Para a adoção da denominação kire teniha, Nagayama acredita que Sôgi tenha escolhido os morfemas teniwoha que tinham a capacidade de "cortar a estrofe. No tratado Bajôshû (c.1475), por outro lado, o monge Shinkei adotou o termo kireji e essa nomenclatura se tornou comum. O tratamento do kireji em Mitsudenshô é uma evolução em relação a o que acontecia em Renrihishô, na opinião de Nagayama. Afinal, o kireji passou a ser abordado como morfema teni(wo) ha e não mais em função do hokku (estrofe de entrada do renga).

\subsection{Teniha como tomari e kireji na poética clássica japonesa}

Vimos que Teniha Taigaishô (Sumário sobre os Teniha), que contém um curto texto de cerca de 640 ideogramas foi o documento que inaugurou a tradição do teniwoha kenkyû ou pesquisas sobre teniwoha, na área de estudos sobre língua no Japão, pois foi a primeira que apresentou explicações lingüísticas, e não exclusivamente poéticas, acerca da morfossintaxe. Entretanto, Teniha Taigaishô era um tratado de poética e, por isso, os temas centrais eram o kire (corte), tomari (parada) e tsuzuki (continuação) no poema waka. E, justamente os teniwoha é que desempenhavam função importante nesses kire, tomari e tsuzuki.

Analisamos, nas referências ao tomari que foram feitas no Teniha Taigaishô, as formas gramaticais chamadas teniwoha. 
Os teniwoha citados no tratado foram os morfemas kakari joshi, de acordo com a terminologia atual: zo, koso, no, ya. No caso deste tratado, a esses kakari joshi correspondiam um conjunto de letras silábicas que integravam palavras com as quais faziam 'par', ou seja, eram musubi na posição final do verso ou da estrofe. Diz-se, por exemplo, no Teniha Taigaishô, que teniha no e ya são iguais ao zo ou as substituem. Elencamos, abaixo, os kakari zo, koso, no e ya, com as respectivas terminações. Após essa lista, trazemos os exemplos que foram citados em Teniha Taigaishô-no Shô (Sumário do Sumário sobre os Teniha, 1483) o qual abreviamos Shô-no Shô.

ZO - u, ku, su, tsu, nu

Shô-no shô: $\quad$ Kaze-zo kototou;

Hana-zo saku;

Tama-zo nasu;

Kasumi-zo tatsu;

\section{NO e YA - u, ku, su, tsu, nu}

Shô-no shô: Tsuma-ya komoreru. Ugu'isu-no naku.

KOSO - e, ke, se, te

Shô-no shô: Hito-mo-koso kike;

Kô-wo-koso utsuse;

Kasumi-koso tate;

Hito-wo-koso omoe;

Uma conclusão preliminar é que os poetas japoneses dessa época tinham percebido que alguns teniwoha exerciam alguma influência sobre a parte final do poema, interpretando-os como recurso de criação poética, e não como fato de língua. Isso porque a língua de comunicação, nesta época, tinha se transformado e era muito diversa daquela utilizada na poesia, que era mais próxima da corrente na Era Antiga quando esse recurso linguístico era comum. O tratado de waka posterior, Anekôjishiki (Método Anekôji) contém explicação semelhante sobre a relação dos teniwoha superiores, ou os kakari, e dos teniwoha inferiores, ou os musubi. Entretanto, os poetas-críticos passaram a adotar outras formas de explicação, mais elaboradas, utilizando a tabela das letras silábicas kana, chamada gojû 'onzu, para demonstrar a fileira de letras que tinham o mesmo som vocálico.

No tratado da poesia renga, Renrihishô, Yoshimoto Nijô (1320-1388) fala da importância dos teniwoha na poética do renga e, no entanto, nele não há explicação razoável sobre o uso e o significado deles. Nesse texto, tampouco ocorrem exemplos de poemas, como acontecia com os tratados sobre o waka. Contudo, dada a natureza de criação do renga, o uso dos teniwoha foi lembrado para uso na posição de fim de verso ou de estrofe. Citamos, abaixo, a forma de aconselhamento para cada teniwoha considerado por Yoshimoto: 
- "a letra $n i$, usada na terminação do verso superior, é boa; mas, na terminação do verso inferior soa mal";

- "a letra te, boa na terminação do verso superior, é ruim, no inferior."

"nunca se deve finalizar o verso com temo e tomo"

"não temos notícia de algum poema com o uso da letra no na terminação do verso"

No parágrafo que trata de hokku (a estrofe de entrada), Yoshimoto citou os teniwoha que davam o efeito de corte (ou kire) na terminação da estrofe:

- "normalmente kana e keri são utilizados (para a terminação da estrofe)"

- "além desses, nashi, kere, nare e ran também são comuns."

- "kana, keri e ran (são teniwoha que) com certeza, dão o corte."

Como no renga a estrofe precisa encerrar a completude de uma 'idéia poética', os poetas se preocupavam com os teniwoha que proporcionassem a autonomia, principalmente para o hokku, a estrofe de abertura. No entanto, elaborar uma estrofe que permitisse manter alguma relação com a anterior também era crucial nessa arte de modo que, mais uma vez, o papel do teniwoha tornava-se importante. Yoshimoto alertou em seu Renrihishô: "Teniwoha é uma coisa importante. Uma estrofe, por excelente que seja, se (o poeta) errar o uso do teniwoha, não consegue se encadear (com a estrofe anterior)"

Em Bajôshû, o monge Shinkei diz: "Na estrofe em que há koso, deve-se sempre 'parar ou terminar' com kere, mas depende muito da estrofe" e exemplificou com uma estrofe que terminava num nome substantivo: "Hotoke koso futatsu-no kawa-no watashi mori (O Buda é o barqueiro [das duas margens] do rio)" Continuou, afirmando que os iniciantes deveriam terminar o hokku (estrofe de entrada) em kana. E o daisan ou terceira estrofe precisava terminar em nite. No entanto, "se contiver koso, será em kere; se tiver zo, em ru; e se for uma pergunta com ya, deve se terminar em ran." Ou seja, o teniwoha foi tratado como recurso para o tomari (parada ou interrupção) da estrofe ou poema, como acontecia na poética do waka.

Os teniwoha citados em Bajôshû foram, portanto: koso e kere; kana e nite; zo em par com ru; ya em par com ran.

No tratado Hakuhatsushû, os teniwoha foram explicados para o uso como kireji (letra de corte) e como tomari (terminação).

Antes de Hakuhatsushû, o monge Senjun (1418-1489), em Senjun Hôgan-no Shihi-no Koto (Segrados das Falas do Monge Senjun, 1411 ou 1476), expôs 18 kireji para serem utilizados nos hokku (estrofes de entrada), segundo Tanabe 1965[1959]. 
Quase os mesmos kireji $i^{2}$ foram elencados em Hakuhatsushû, no parágrafo intitulado "Hokku kireji 18-no koto (Sobre os 18 kireji de hokku)" e os poemas-estrofes exemplificados também são os mesmos.

No parágrafo intitulado " $z o, k a, y o$-no sanji-no koto (Sobre as três letras $z o$, $k a$ e $y o)$ ", o autor orienta para que a estrofe contendo essas letras deveria terminar em te, como em "ukiyozoto omou namidani sode nurete. Mais adiante, afirma-se que "existem 5 formas de se terminar com nite", ou seja, quando há wo, ha, mo, karanu e raba, e que, caso não tenham essas letras, termine-se com kana.

Os teniwoha dos tratados sobre renga desta pesquisa podem ser como dispostos nos quadros seguintes, na classificação gramatical elaborada por Yoshio Yamada (1873-1958), cujos termos estão na primeira fileira, em cinza e acompanham equivalentes em português:

\section{Quadro 2: Os teniwoha de Renrihishô organizados segundo classificação gramatical de Yamada}

\begin{tabular}{|c|c|c|c|}
\hline $\begin{array}{c}\text { Setsuzokujoshi } \\
\text { Morfema conectivo }\end{array}$ & $\begin{array}{c}\text { Shûjoshi } \\
\text { Morfema final }\end{array}$ & $\begin{array}{c}\text { fukugobi (jodôshi) } \\
\text { Desinência complementar }\end{array}$ & $\begin{array}{l}\text { Keiyôshi } \\
\text { Adjetivo }\end{array}$ \\
\hline$n i$ & kana & $\begin{array}{c}\text { keri } \\
\text { flexão terminativa }\end{array}$ & nashi \\
\hline te & & $\begin{array}{c}\text { kere } \\
\text { flexão izenkei }\end{array}$ & \\
\hline temo & & $\begin{array}{c}\text { ran } \\
\text { flexão terminativa ou adjetiva }\end{array}$ & \\
\hline tomo & & $\begin{array}{c}\text { nare } \\
\text { flexão terminativa ou adjetiva }\end{array}$ & \\
\hline
\end{tabular}

\section{Quadro 3: Os teniwoha em Bajôshû organizados segundo classificação gramatical de Yamada}

\begin{tabular}{|c|c|c|c|}
\hline $\begin{array}{c}\text { Kakarijoshi } \\
\text { Morfema modal }\end{array}$ & $\begin{array}{c}\text { Shûjoshi } \\
\text { Morfema final }\end{array}$ & $\begin{array}{c}\text { Fukugobi (jodôshi) } \\
\text { Desinência complementar }\end{array}$ & Desinência verbal \\
\hline koso (-kere) & kana & kere & $r u$ \\
\hline$z o(-r u)$ & nite & ran & \\
\hline$y a(-r a n)$ & & & \\
\hline
\end{tabular}

2. Ao invés de $n i$ do Senjun, em Hakuhatsushû, temos ikani. Na verdade, o ni faz parte do 'advérbio' ikani. Está correta a 'segmentação' em Hakuhatsushû. 


\section{Quadro 4: Os teniwoha em Hakuhatsushû segundo classificação gramatical de Yamada}

\begin{tabular}{|c|c|c|c|c|c|}
\hline $\begin{array}{c}\text { Kakarijoshi } \\
\text { Morfema } \\
\text { modal }\end{array}$ & $\begin{array}{c}\text { Shûjoshi } \\
\text { Morfema } \\
\text { final }\end{array}$ & $\begin{array}{c}\text { Fukugobi } \\
\text { Desinência } \\
\text { complementar }\end{array}$ & $\begin{array}{l}\text { Keiyôshi } \\
\text { Adjetivo }\end{array}$ & $\begin{array}{l}\text { Dôshi } \\
\text { Verbo }\end{array}$ & $\begin{array}{l}\text { Fukushi } \\
\text { Advérbio }\end{array}$ \\
\hline$z o$ & gana & $\begin{array}{c}\text { keri: } \\
\text { flexão terminativa }\end{array}$ & $\begin{array}{c}\text { shi: } \\
\text { flexão } \\
\text { terminativa }\end{array}$ & $\begin{array}{c}k e: \\
\text { flexsão imperativa }\end{array}$ & ikani \\
\hline$y a$ & mogana & $\begin{array}{c}t s u: \\
\text { flexão terminativa }\end{array}$ & & $\begin{array}{c}s e: \\
\text { flexão imperativa }\end{array}$ & \\
\hline \multirow[t]{4}{*}{$k a$} & yo & $\begin{array}{c}n u: \\
\text { flexão terminativa }\end{array}$ & & $\begin{array}{c}h e: \\
\text { flexão imperativa }\end{array}$ & \\
\hline & & $\begin{array}{c}z u: \\
\text { flexão terminativa }\end{array}$ & & $\begin{array}{c}r e: \\
\text { flexão imperativa }\end{array}$ & \\
\hline & & $\begin{array}{c}j i: \\
\text { flexão terminativa }\end{array}$ & & & \\
\hline & & $\begin{array}{c}\text { ran: } \\
\text { flexão terminativa }\end{array}$ & & & \\
\hline
\end{tabular}

\section{Teniwoha - dos Tratados Poéticos para os Estudos Gramaticais}

Em meados do século XIX, quando a política de isolacionismo do governo Tokugawa se afrouxou, as ciências do mundo ocidental entraram oficialmente no Japão e foram absorvidos avidamente pelos japoneses. Entretanto, a continuidade do comércio com a Holanda e China nos séculos XVII a XVIII, permitiu a introdução do que muito se fazia intelectual e culturalmente na Europa durante todo esse período. Nos estudos sobre línguas, o contato com os holandeses permitiu a aquisição de manuais gramaticais do holandês e, graças aos intérpretes e tradutores japoneses dessa língua, houve tentativas de descrever a gramática japonesa segundo o modelo europeu. Embora timidamente, acontecia a aprendizagem também do inglês. Segundo Furuta (1992 [1976]), Randai Iida, em Tenihakô (Considerações sobre Teniha), de 1828, é um dos primeiros a elaborar uma gramática do japonês segundo a gramática das partes do discurso de herança greco-latina. Esse manual é uma tentativa de explicar os morfemas teniwoha sob a ponto de vista dos casos. Shigenobu Tsurumine (1788-1859) tentou um trabalho mais abrangente, em Gogaku Shinsho (Novos Escritos sobre Estudos de Língua, 1833), ao classificar as palavras japonesas em 9 tipos e referir-se à sintaxe. Eram, porém, tentativas isoladas pois são trabalhos da primeira metade do século XIX, mas que aumentaram após a abertura oficial do Japão à diplomacia ocidental a partir de 1867. O Período Meiji, que começou nesse ano, foi um tempo em que, assim como em outras áreas, o estudo da gramática conheceu o embate das tradições japonesa e européia e das tendências de estudos individuais. A palavra bunpô 文法 ganhou o significado de 
Spraakkunst e de grammar e, assim teve-se o nascimento da palavra bunpô como gramática no Japão. E, dentro da gramática, as várias tentativas de classificação das palavras têm um final com Fumihiko Ôtsuki (1847-1928). O mesmo não se pode dizer da definição de bun (frase, sentença ou oração) que oscilou por mais algum tempo devido às indefinições também da gramática ocidental sobre a questão.

Fumihiko Ôtsuki, autor do dicionário Genkai (Oceano de Palavras, 1891), que se tornou o modelo dos dicionários japoneses até hoje, é considerado também o gramático que conseguiu conciliar a tradição japonesa e a européia de estudos sobre a gramática do japonês (conforme, por exemplo Tsukishima 1988 [1980]) e estabeleceu as oito classes de palavras, classificação essa que chamou de gobetsu (語別 tipo de palavra) acompanhado da tradução inglesa parts of speech. No prefácio do dicionário Genkai acima citado, na parte intitulada "Gohôshinan" (Ôtsuki 1891), Ôtsuki faz uma exposição sobre os oito tipos de palavras (para "palavra" usou as denominações hinshi, gengo, ou tango, sem a preocupação em defini-la como uma unidade gramatical). São elas: meishi (nome) que inclui daimeishi (pronome) e sûshi (numeral), dôshi (verbo), keiyôshi (adjetivo), jodôshỉ ${ }^{3}$, fukushi (advérbio), setsuzokushi (conectivo), teniwoha ${ }^{4}$ e kandôshi (interjeição).

Dentro da tradição japonesa antes do Período Meiji, Michitoshi Toga-no-I (1725-1785) foi quem primeiro tratou separadamente os teniwoha segundo o critério da existência ou não de variação flexional, em Teniha Abikizuna (Corda para Puxar o Fio do Teniha, 1770). Hirokage Togashi (1793-1872), de igual maneira, subdividiu os teniwoha em hataraki teniwoha (teniwoha com variação desinencial) e suwari teniwoha (teniwoha sem variação desinencial), em Kotoba-no Tamahashi (O Nó das Palavras, 1826), segundo Nagano 1988 [1980] e outros, os quais correspondem, grosso modo, aos morfemas jodôshi e aos joshi, respectivamente.

Mas Ôtsuki foi quem deu praticamente o 'formato' de jodôshi que ainda hoje persiste, ao defini-lo da seguinte maneira: "jodôshi é uma palavra que se fixa após a flexão de um verbo para acrescentar (outros) significados, além de se fixar a outras palavras. ... Possuem significados como os verbos mas não são utilizados no começo da sentença de forma autônoma, mas sempre fixo após outras palavras e no interior da sentença" (Ôtsuki 1891: 82) e ao classificá-lo de acordo com o significado que determina à palavra na qual se fixa.

Ao morfema gramatical joshi, Ôtsuki manteve a denominação teniwoha (abreviadamente teniha) que define como "uma palavra que se encontra no interior

3. Na terminologia de Ôtsuki, jodôshi é a tradução de auxiliry verb. Mas não são verbos como são os dôshi, mas sim morfemas gramaticais.

4. Ôtsuki reuniu, no grupo de palavras que denominou teniwoha, apenas os morfemas gramaticais sem variação flexional, chamados atualmente de joshi. 
da língua ${ }^{5}$, ligando palavras de cima ao debaixo e acrescentando diversos significados. O teniha é uma forma curta e não é utilizado de forma autônoma." (Ôtsuki 1891.94). Numa nota, Ôtsuki explicou a origem do termo teniwoha que é a mesma da dada, pela primeira vez, por Michitoshi Toga-no-i em Teniha Abikizuna acima citado. Segundo Toga-no-i, o termo teniwoha ou teniha derivou de uma ilustração utilizada desde a antigüidade para a leitura de textos chineses (Toga-no-i, 1770: 3). Tratava-se de um quadrado contendo marcas nos seus ângulos e no centro das linhas dos lados. Esses pontos correspondiam, cada um, a um determinado morfema gramatical. A posição do ponto, colocado sobre o ideograma, indicava a partícula que se fixava nele, o que determinava, por sua vez, a função gramatical desse ideograma-palavra na sintaxe japonesa.

Ôtsuki subclassificou, primeiramente, os teniwoha segundo o tipo de palavra na qual se fixa:

- teniwoha que se fixam nos meishi (nomes)

- teniwoha que se fixam em diversas palavras e

- teniwoha que se fixam nos dôshi (verbos)

Yoshio Yamada (1873-1958) inaugurou o Bunpôgaku ou Estudos Gramaticais, que exerceria, daí em diante, papel fundamental nos estudos sobre a língua japonesa no Japão, o Kokugogaku (Estudos sobre a Língua Nacional), não sendo exagerado afirmar que, em um período após a Segunda Grande Guerra, Bunpôgaku confundiu-se com o Kokugogaku propriamente dito. A partir de Yamada, a gramática japonesa despiu-se do caráter essencialmente normativo e tornou-se científico, segundo Furuta (1992 [1976]).

É verdade que Ôtsuki deu um 'acabamento' à classificação de palavras do japonês, conciliando, como se disse, as tradições japonesa e ocidental. No entanto, o critério, quando houve, dessa classificação foi o lexical-semântico das gramáticas européias. À esta situação, Yamada propôs uma teoria gramatical que indicasse os contornos do critério lexical-semântico que fosse específico das palavras japonesas. Em Nihon Bunpôron (Teoria da Gramática Japonesa, 1908), Yamada começou pela definição de go ou tango (palavra) e $k u$ (frase) e elaborou a seguinte classificação de palavras:

5. Ôtsuki usou gengo que traduzimos por língua, mas neste caso parece corresponder mais à sentença. 


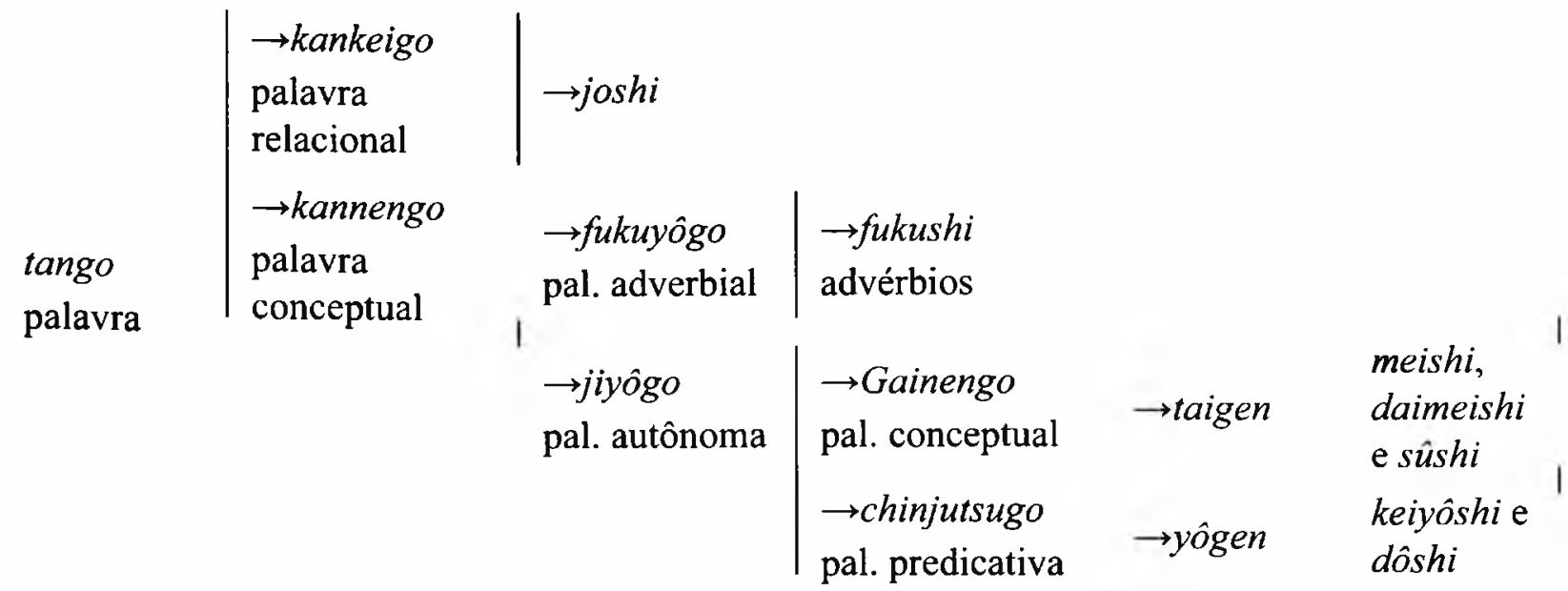

E foi Yamada também quem estabeleceu critérios mais precisos para a subclassificação dos teniwohalteniha de Ôtsuki, que foi renomeado de joshi e que ficou do seguinte modo, com os novos termos na coluna mais à direita:

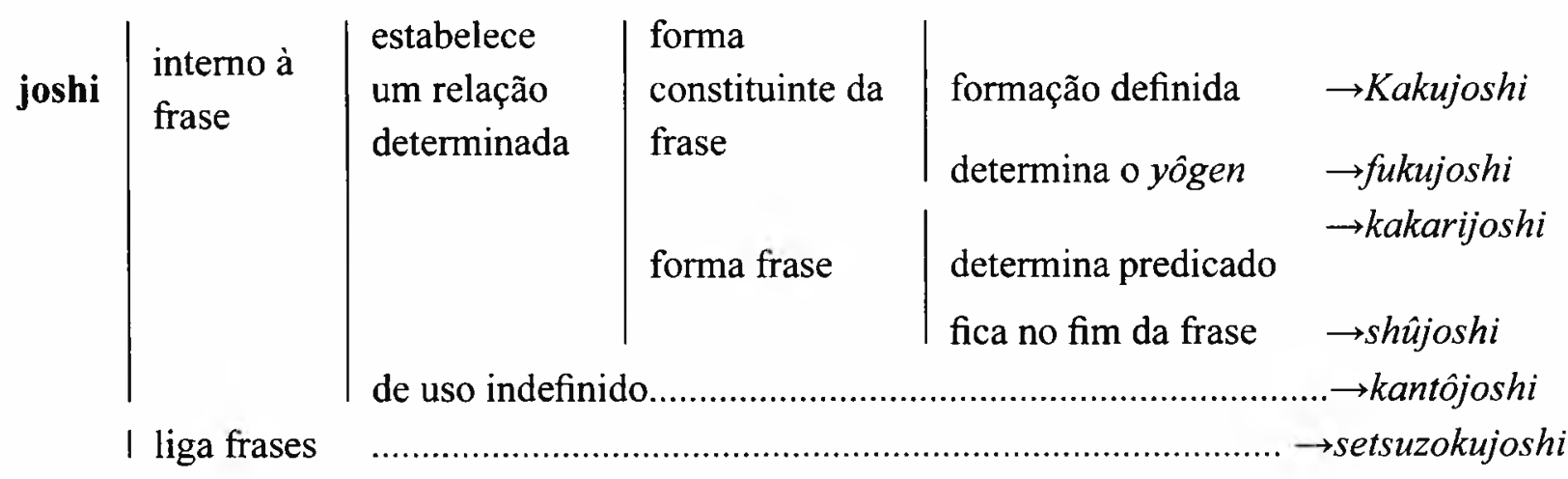

Na mesma época de Ôtsuki e Yamada ${ }^{6}$, Daizaburô Matsushita (1878-1935) desenvolveu a sua teoria gramatical do japonês que tem por base a seguinte idéia: o shinen (pensamento) estrutura-se em dois níveis: kan'nen (conceito) e dantei (julgamento). A língua, por sua vez, possui três níveis, genji (palavra-matéria), shi (palavra) e danku (sentença). Pode-se esquematizar o pensamento de Matsushita da seguinte maneira:

6. As teorias gramaticais e também de classificação de palavras dos gramáticos japoneses que tiveram papel importante na formação da Linguística Gramatical japonesa no início do século XX foram estudadas pelo Grupo Interinstitucional de Estudos da Língua Japonesa - GRIELJ que logo lançará um livro com os resultados da pesquisa. 
Níveis do "pensamento'

(shinen 思念)

Níveis de língua

(gengo 言語)

kan nen (観念)

genji (原辞)

$\operatorname{shi}($ (詞)

dantei (断定)

| danku (断句)

Aproximando à nossa terminologia gramatical, genji seria a matéria-prima que resultará um shi, 'constituinte imediato' da sentença, e essa sentença é o danku. Os morfemas gramaticais joshi e jodôshi, nesta tipologização de Matsushita, seriam os genji.

Após mais de meio século à sombra de Yamada, Shinkichi Hashimoto (1882-1945) e Motoki Tokieda (1900-1967), Matsushita e a sua teoria gramatical estão sendo revistas atualmente, por conta de mudança na orientação de pesquisa, do Kokugogaku (Estudos sobre a Língua Nacional) para Nihongogaku (Estudos sobre a Língua Japonesa). Portanto, a orientação agora é analisar a morfossintaxe do japonês a partir do nível do $s h i$ 詞 de Matsushita ${ }^{7}$ Entendemos que esse shi corresponte ao sintagma.

\section{Considerações Finais}

Para este artigo apresentamos os primeiros tratados da poética renga que possuem alguma referência aos teniwoha, os quais foram entendidos como recursos de kire (corte) e tomari (interrupção) de versos ou estrofes desse gênero literário. Gramaticalmente, o termo teniwoha abrangia, na criação poética do renga, diversos morfemas gramaticais e também alguns lexicais que se posicionavam em fins de verso ou estrofe. Como vimos nos Quadros 2, 3 e 4, os morfemas gramaticais eram os conectivos, finais e modais ${ }^{8}$, além de desinências verbais e adjetivais; os morfemas lexicais utilizados como teniwoha foram o adjetivo "nashi" e o advérbio "ikani"

Os chamados teniha ou teniwoha em diferentes épocas no Japão foram inicialmente identificados como recurso do fazer poético, tanto dos poemas waka e poemas renga, responsáveis pela completude do verso ou estrofe no nível do

7. Segundo Mayumi Kudo, da Universidade de Osaka, durante seu minicurso no XIII Encontro de Professores Universitários de Língua, Literatura e Cultura Japonesa, dias 28 e 29 de agosto de 2.002, no Centro de Estudos Japoneses da USP.

8. Pela classificação de palavras criada por Yamada (1908), correspondem às palavras denominadas setsuzokujoshi, shûjoshi e kakarijoshi. 
significante e também no do significado. Os teniha ou teniwoha que assim foram destacados e explicados, sempre como parte dos poemas, passaram a ser explicados como parte integrante de orações ou sentenças para cuja constituição desempenhariam papel principal.

Posteriormente, apresentaremos os resultados de nossas reflexões acerca dessa transferência de termos e definições do âmbito da criação poética para o da produção lingüística.

\section{Referências Bibliográficas}

FURUTA, Tôsaku. 1992 [1976]. 8-Bunpô Kenkyû-no Rekishi 2 (8 História das Pesquisas Gramaticais 2). In Ôno, Susumu \& Shibata, Takeshi. Iwanami Kôza Nihongo 6, Bunpô I (Cursos Iwanami [de] Língua Japonesa 6, Gramática I). 3a. edição. Tóquio: Iwanami shoten, pp. 299-356.

NAGANO, Masaru. 1988 [1980]. Jodôshi. In Kokugogakkai. Kokugogaku Daijiten (Grande Dicionário de Estudos da Língua Nacional Japonesa). 6a. impressão. Tóquio: Tôkyôdô, pp. 523-524.

NAGAYAMA, Isamu. 1963. Capítulo 5 - Kireji setsu no genkyû to tenkai (Origem e Evolução da Teoria do Kireji). In Kokugo Ishikishi no Kenkyû (Pesquisa sobre a Evolução da Percepção sobre a Língua Nacional Japonesa). Tóquio: Kazama shobô, pp. 685-747.

ÔKA, Makoto. 1991. The Colors of Poetry: Essays on Classic Japanese Verse. Tradução de Takako U. Lento e Thomas V. Lento. Estados Unidos: Katydid Books.

ÔTSUKI, Fumihiko. 1891. Gohôshinan (Instruções sobre Gramática). In de Palavras). Tóquio: publicação particular por Ôtsuki Fumihiko, pp. 1-79.

TASHIRO-PEREZ, Eliza A. 2009. Poemas waka e os tratados sobre teni(wo)ha na era medieval japonesa. In Estudos Japoneses no. 29. São Paulo: Centro de Estudos Japoneses da USP, pp. 25-44.

TANABE, Masao. 1965 [1959]. Kokugogakushi (História dos Estudos sobre a Língua Nacional Japonesa). Edição ampliada. Tóquio: Ôfûsha.

TSUKISHIMA, Hiroshi. 1988 [1980]. Ôtsuki Fumihiko. In Kokugogakkai (org.). Kokugogaku Daijiten (Grande Dicionário de Estudos da Língua Nacional Japonesa). 6a. edição. Tóquio: Tôkyôdô shuppan: 85 .

YAMADA, Yoshio. 1908. Nihon Bunpôron (Teoria da Gramática Japonesa). Tóquio: Hôbunkan. 